\title{
METODOLOGIA PARA IMPLEMENTAÇÃO DE CURRÍCULO INTEGRADO E POR COMPETÊNCIAS EM CURSOS HÍBRIDOS
}

\author{
JAGUARIÚNA/SP MAIO/2018 \\ Silvio Petroli Neto - UniFAJ - spetroli@faj.br \\ José Carlos Pacheco Coimbra - UniFAJ - coimbra@faj.br \\ Tipo: Relato de Experiência Inovadora (EI) \\ Categoria: Métodos e Tecnologias \\ Setor Educacional: EDUCAÇÃO SUPERIOR
}

\begin{abstract}
RESUMO
O acesso fácil à informação e ás novas configurações sociais mudaram o perfil dos ingressantes nos cursos superiores. Com isso, métodos tradicionais de transferência de informação já não mais atendem aos anseios desses estudantes e nem às necessidades do mercado de trabalho que os absorvem. Nesse sentido, há a necessidade de atualização dos currículos escolares para que trabalhem cada vez mais os conceitos de aprendizagem significativa, promovendo a autonomia dos estudantes a medida que trabalham com problemas reais e desafiadores. Além disso, esses currículos devem ser capazes de trabalhar competências que vão além das meramente conceituais, havendo necessidade urgente de desenvolvimento de competências procedimentais e atitudinais. Promover essas transformações vai além da modificação da metodologia utilizada pelos professores em sala de aula, passando a ser necessária a transformação do currículo dos cursos de graduação, que deixam de ser currículos conteudistas e passam a ser currículos integrados, por competência, nos quais os saberes já não estão agrupados em disciplinas mas sim aplicados em projetos que permitam ao estudante relacioná-los às suas aplicações práticas e reais. Esse trabalho traz uma proposta de currículo inovador, integrado e por competências para implementação de cursos de graduação no formato híbrido.
\end{abstract}

Palavras-chave: Inovação Acadêmica, currículo por competência, metodologias ativas 


\section{Introdução}

Com o progresso da tecnologia, a exigência de educação necessária para usá-la com eficácia cresce, e as instituições de ensino devem inovar para acompanhar o ritmo desta evolução. Dessa forma, a educação e a tecnologia participam de uma "corrida". Quando a educação fica atrás do progresso tecnológico, as pessoas não são qualificadas para as vagas de trabalho oferecidas pelo mercado e o trabalho realizado não é tão produtivo nem de boa qualidade como poderia ser.

Com isso, a desigualdade econômica cresce, pois aqueles com meios de obter uma educação melhor podem assegurar mais oportunidades de avanço e aqueles sem a possibilidade de uma educação altamente eficaz têm pouca esperança de melhorar sua situação econômica. Por isso, tanto as pessoas quanto a sociedade sofrem com desemprego, subemprego, distribuição desigual de renda, estresse pessoal e inquietação social.

Isso pode gerar uma insatisfação em relação à qualidade dos processos de ensino e aprendizagem que predominam na universidade contemporânea. Nesse contexto, nos chamam a atenção as evidências referentes aos altos índices de evasão e insatisfação do estudante, bem como a percepção sobre a possível irrelevância de boa parte dos conteúdos que são ministrados, além das lacunas de competências na formação pessoal e profissional de nossos estudantes.

O que os estudantes deveriam aprender para ter sucesso neste mundo em que a maioria das tarefas rotineiras e impessoais é controlada por sistemas computadorizados? A memorização de grandes quantidades de conteúdo ainda é necessária nesta era em que podemos encontrar a resposta para tudo na internet?

Existem muitas respostas aceitáveis para essas perguntas, mas raramente elas se baseiam apenas no ensino de mais conhecimentos e sim no aprendizado de mais conhecimentos relevantes, em como aplicar o conhecimento de maneiras novas e diferentes e no desenvolvimento de outras três dimensões do aprendizado: habilidades, qualidades do caráter e estratégias de meta-aprendizado.

Este trabalho apresenta uma proposta de currículo integrado e por competências para implementação de cursos superiores em formato híbrido que possibilite trabalhar competências que vão além das meramente conceituais, mas que permita trabalhar competências procedimentais (aplicação de conceitos em projetos reais) e atitudinais.

\section{Referencial teórico}


As transformações sociais acontecem cada vez mais rápido e são cada vez mais profundas. O motivo disso passa pelo desenvolvimento tecnológico que agiliza todo esse processo de mudança e que, impulsionado pelo mercado, tem a necessidade de vender-nos esses produtos e "pegam pesado" nesse objetivo. Hoje, qualquer criança com mais de um ano é capaz de manusear um celular ou um tablet. Esse indivíduo, quando adulto, não terá dificuldade nenhuma para ter acesso à informação. Portanto, não adianta queremos que eles fiquem dentro de uma sala de aula, ouvindo um professor falar aquilo que, há minutos, estava em suas mãos por meio de um vídeo, um texto, uma animação, um jogo. Enfim, não faz sentido nenhum para ele todo esse processo.

Ao pensarmos nisso, percebemos que a necessidade de mudança do processo de aprendizagem vem da mudança da sociedade como um todo e das transformações promovidas pela inserção de tecnologia em nosso cotidiano.

Portanto,

\begin{abstract}
Os métodos tradicionais, que privilegiam a transmissão de informações pelos professores, faziam sentido quando o acesso à informação era difícil. Com a Internet e a divulgação aberta de muitos cursos e materiais, podemos aprender em qualquer lugar, a qualquer hora e com muitas pessoas diferentes. Isso é complexo, necessário e um pouco assustador, porque não temos modelos prévios bem sucedidos para aprender de forma flexível numa sociedade altamente conectada. (apud MORAN, 2013).
\end{abstract}

Essa mudança de comportamento privilegia projetos de aprendizagem que promovam a autonomia do estudante, utilizando a sala de aula como ambiente de desenvolvimento de projetos práticos e com foco no mercado, motivando o estudante na aplicação do seu conhecimento.

Já temos indicadores que mostram que o ensino baseado em projetos, por exemplo, é uma solução para as escolas que querem romper com o conservadorismo das práticas pedagógicas repetitivas, promovendo ações de transformação dos processos de aprendizagem (MASSETTO, 2012).

A Figura 1 representa o resultado de um estudo realizado por professores do MIT (Massachusetts Institute of Technology) em parceria com a Universidade de Harvard, no qual um grupo de estudantes teve suas atividades cerebrais monitoradas em seu dia a dia por uma semana, e os resultados observados demonstram que precisamos realmente promover uma mudança no que estamos fazendo em nossas salas de aula. Observem que, no momento em que as crianças estão em sala de aula, a atividade cerebral delas equivale ao momento em que encontram-se, por exemplo, assistindo TV, 
de forma passiva e sem absorver praticamente nada do que estão vendo/ouvindo.

Figura 1 - Monitoramento de atividade cerebral durante o dia a dia de um grupo de estudantes. (Poh M.Z et al, 2010)

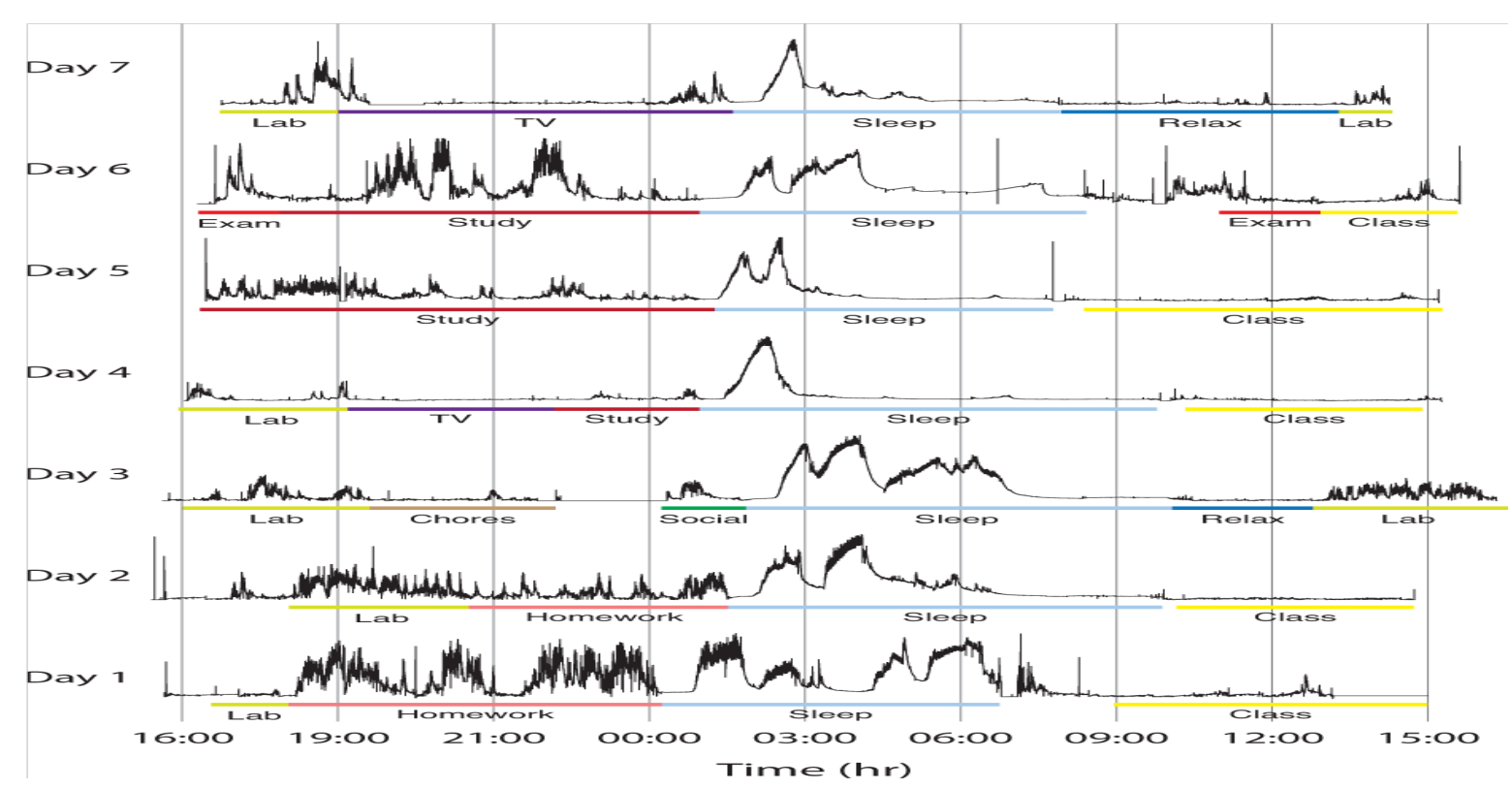

Um olhar mais cuidadoso do trabalho realizado por alguns colegas no ensino superior revelará que já há muito tempo essas estratégias ativas fazem parte do dia a dia da escola. São experiências nascidas, com frequência, de forma empírica, algumas sem fundamentação teórica que as sustente, mas elaboradas a partir da percepção de que, se o estudante não participar de forma mais ativa em sala de aula ou fora dela, a aprendizagem não terá um significado que a torne efetiva (MATTASOGLIO \& SOSTER, 2017)

Como, para que o que estamos discutindo aqui possa acontecer, precisamos promover técnicas de estudo autônomo para os estudantes, uma vez que eles terão que ter contato com o conteúdo extraclasse para que, na sala de aula, os estudantes possam aplicar esses conteúdos, faz-se necessário que utilizemos de técnicas de educação online, já que essa modalidade de ensino possui técnicas e ferramentas que permitem que conteúdos sejam disponibilizados de forma organizada e efetiva.

Surge, portanto, o conceito de Blended Learning (ensino híbrido), ou seja, um processo que une o melhor da educação on-line com o melhor da educação presencial em um híbrido, cujos resultados e eficiência no aprendizado são promissores.

Clayton Christensen (CHRISTENSEN \& HORN, 2013) define como características de algo que seja híbrido: 
1. Ele apresenta tanto a nova quanto a antiga tecnologia, enquanto uma inovação puramente disruptiva não oferece a tecnologia anterior em sua forma plena;

2. Ele busca atender aos clientes já existentes, em vez dos não-consumidores - ou seja, aqueles para os quais a alternativa ao uso da nova tecnologia seria não utilizar nada;

3. Ele procura ocupar o espaço da tecnologia pré-existente. Como resultado, a obrigação de se atingir um desempenho que supere as expectativas dos clientes existentes é bastante alta, uma vez que o híbrido precisa realizar o trabalho pelo menos tão bem quanto o próprio produto anterior, se analisado pela definição original de desempenho. Por outro lado, as empresas bem-sucedidas na implementação de inovações disruptivas geralmente assumem as capacidades da nova tecnologia como um dado e procuram mercados que aceitem a nova definição sobre o que é bom;

4. Seu uso tende a ser mais simples que o de uma inovação disruptiva. Ele não reduz significativamente o nível de renda e/ou conhecimento necessários para comprá-lo e operá-lo.

Essa mudança do processo de aprendizagem é algo irreversível, e seremos pioneiros quanto antes conseguirmos fomentar tais culturas em nossas instituições de ensino.

\section{Procedimentos Metodológicos}

Para operacionalização produtiva do trabalho, alguns documentos são indispensáveis, sendo eles: planos de ensino das disciplinas do curso tradicional, Diretrizes Curriculares do Curso e Diretrizes ENADE, referenciais teóricos e anotações pessoais, quadro branco, folhas de cartolina e papel pardo, canetas coloridas.

Trabalhar com os planos de ensino das disciplinas tradicionais é útil para a realização de uma verdadeira arqueologia do curso, sendo preciso compreender o que a abordagem de cada disciplina representava para o curso tradicional e projetar, a partir disso, as capacidades a serem desenvolvidas para a formação discente. Veja-se que, aqui ainda, nos remetemos à expressão "disciplina", haja vista estarmos imersos em planos de ensino do modelo tradicional e, por isso, é necessário quebrar algumas ancoragens, mas tal retomada é importante para refinar o olhar para a educação por competências e projetos e superar o modelo disciplinar de pensar.

Nesse sentido, ilustrar com um exemplo pode ajudar a compreensão. Entre as várias disciplinas que foram dissecadas, trabalhou-se a disciplina de "Elaboração de Cardápios", do curso de Gastronomia sendo a pergunta-chave: "Quais as capacidades 
devem ser desenvolvidas para que o aluno tenha plena competência para a tal elaboração?". Ao listar tais capacidades necessárias, restou muito claro que muitas delas eram convergentes entre si, podendo ser trabalhadas dentro da proposta mais sistêmica de educação por projetos, ressignificando e personalizando a aprendizagem do estudante.

Assim, a partir do exemplo acima destacado e do cruzamento com capacidades de outras disciplinas, ficou clara a importância do desenvolvimento de competências de compreensão de contextos culturais, antropológicos e históricos no curso, fato esse que escapa da percepção do discente num curso disciplinar tradicional, no qual o estudante tende a tratar as disciplinas com abordagem histórica-antropológica como secundárias. No ensino híbrido, por projetos, mais cedo ou mais tarde, o estudante sentirá a necessidade de se aprofundar na temática, e essa permeará toda a sua formação para, entre outras coisas, formular um cardápio inovador ou criar um novo conceito gastronômico.

Após feita a arqueologia do curso, é hora de dissecar as competências das Diretrizes Nacionais de Curso, bem como, das diretrizes ENADE, de modo a estabelecer uma relação direta entre as disciplinas que envolvem cada competência, sendo trabalhadas semestre a semestre, visando tratar de forma mais objetiva esse enquadramento.

Destaca-se, ainda, que esse processo não envolve a perspectiva sistêmica em que o estudante se apropria dos conteúdos, habilidades e competências no decorrer de todo do curso e não rompe, ainda, com os conceitos de disciplinas. Nesse ponto, cujo foco é o processo de desconstrução, ao fazer tanto a arqueologia das disciplinas quanto a dissecação das competências, começou-se a responder a seguinte questão: "O QUE MEU ESTUDANTE NÃO PODE DEIXAR DE SABER AO TÉRMINO DO CURSO?". Conforme as respostas se configuravam, estabeleceram-se quais são as competências básicas iniciais que o estudante deve desenvolver para a sequência do curso, e aqui já nos referimos ao curso prospectado para o padrão proposto.

A partir dessa compreensão, foram estabelecidos os projetos de curso (Projeto Guardachuva e suas derivações), nos quais os discentes desenvolvem as competências básicas, em se tratando do primeiro semestre, criando uma linha de evolução, que pode ser pensada a partir de eixos, que vai constituindo a formação integral do egresso. Ou seja, após a arqueologia das disciplinas e dissecação de competências, parte-se para a formulação, ainda que incipiente, dos projetos de curso, que chamaremos aqui de prospecção de projetos. 
Com a prospecção de projetos, começa-se a definição dos conceitos necessários para que o estudante possa adquirir as competências necessárias à sua formação, além disso, passa-se a entender as formas como os estudantes poderão personalizar seus estudos e aprofundamentos, utilizando competências específicas e competências complementares, ganhando espaço de autonomia intelectual. Esquematicamente, considerando a ideia de passos a serem seguidos, poderia se definir na Figura 2.

Figura 2: Percurso de construção do modelo

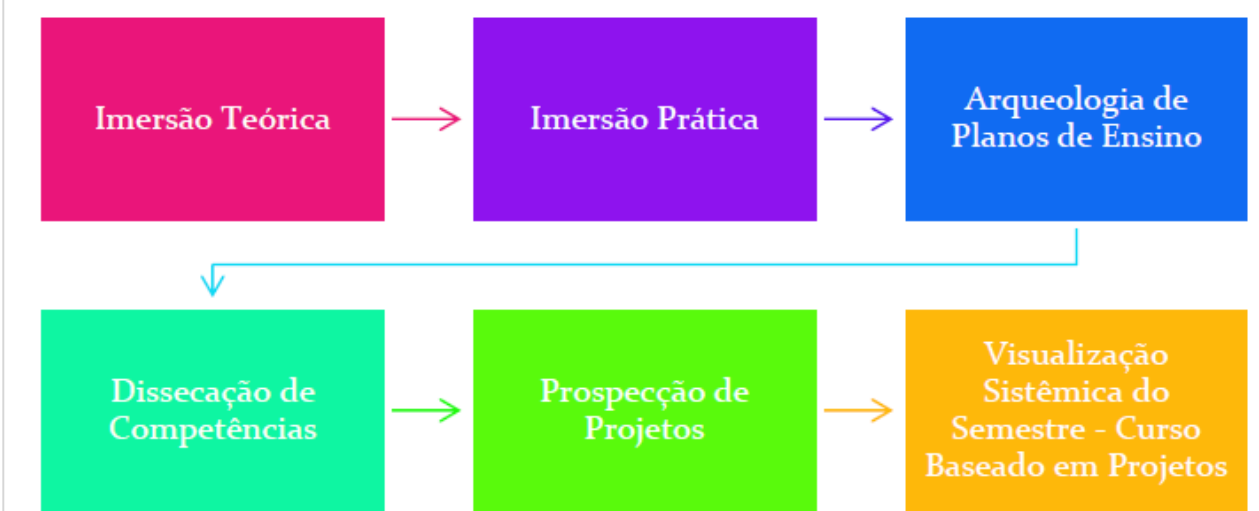

A fase de prospecção de projetos visa possibilitar uma visão sistêmica do curso, além de permitir enxergar a exequibilidade de uma proposta pedagógica dissociada de disciplinas, lembrando-se de que tal prospecção deve ser feita semestre a semestre, sempre definindo competências e habilidades que devem ser trabalhadas pelos estudanres a capa projeto.

Após a definição mais plena possível de tais competências e habilidades, pode-se observar que as mesmas são naturalmente inseridas nas atividades como aprendizagens a serem realizadas, construindo o todo representado anteriormente. Somente a partir daí é que se estabelecem os conceitos teóricos (conteúdos) necessários para a elaboração do projeto e, consequentemente, para o desenvolvimento das competências. Tais conceitos são divididos em blocos, separados de forma a comporem conteúdos obrigatórios, conteúdos intermediários e conteúdos cuja eleição é de livre escolha discente.

\section{Apresentação e discussão dos resultados}

Como resultado do trabalho, obteve-se um modelo de currículo que está em funcionamento em alguns cursos da instituição e que serão expandidos, gradativamente, para os demais.

O currículo no novo modelo não está definido a partir de conceitos que estão divididos em disciplinas, por exemplo. Dessa forma, a matriz curricular é definida com base nas 
competências e habilidades descritas nas diretrizes curriculares de cada curso e distribuídas por cada colegiado ao longo dos semestres. Os conteúdos, que são chamados aqui de referenciais de aprendizagem, são disponibilizados aos estudantes como subsídios para o desenvolvimento do projeto. Esse processo está ligado à teoria da aprendizagem significativa, uma vez que o estudante vê a importância de cada conceito à medida que o aplica em seu próprio projeto (o conceito passa a ter um porquê). $\mathrm{O}$ aprendizado e, consequentemente, o desenvolvimento das competências e habilidades definidas no semestre ficam relacionados ao desenvolvimento dos projetos, cuja solução se dá através da realização de 3 atividades:

1. Atividade autodirigida (AAD) - momento em que o estudante tem contato com os conceitos, busca informação, faz inferência sobre os mesmos e adquire conhecimento dos conteúdos teóricos relativos ao desenvolvimento do projeto. Todo conceito (referencias de aprendizagem) está disponível em um Ambiente Virtual de Aprendizagem em forma de texto, vídeos, gráficos e exercícios de fixação. Ele fica disponível durante todo o semestre, e o estudante pode voltar a ele sempre que tiver necessidade;

2. Prática Orientada para Desenvolvimento de Competência (PODC) - esse é o momento no qual o especialista (docente) trabalha determinados conceitos com os estudantes de forma mais efetiva, por meio de uma prática em sala de aula, da demonstração da aplicação de determinados conceitos ou de laboratórios;

3. Preceptoria - nesse momento, os estudantes estarão debruçados na solução de seus próprios projetos, e o professor passa a ter um papel de orientador do processo, ouvindo individualmente cada estudante e buscando auxiliá-lo na solução dos problemas que levam à construção final do projeto.

Isso posto, a matriz de cada curso é simples, composta pelo projeto e pelas três atividades descritas acima. Esses quatro elementos se repetem ao longo dos semestres do curso, alterando-se apenas 0 projeto (e consequentemente as competências trabalhadas) e adicionando-se alguns elementos referentes à legislação específica de cada curso, como atividades complementares, estágios e trabalhos de conclusão de curso. Um exemplo pode ser visto na Figura 3, que mostra o primeiro semestre do curso de gastronomia.

Figura 3 - Primeiro semestre do curso de gastronomia 


\begin{tabular}{|l|c|}
\hline $1^{\circ}$ Semestre & 200 \\
\hline Projeto: Pré-preparo em Gastronomia e Confeitaria & 50 \\
\hline Atividade Autodirigida em Gastronomia e Confeitaria & 50 \\
\hline Prática orientada para desenvolvimento de competências em Gastronomia e Confeitaria & 100 \\
\hline Preceptoria em Gastronomia e Confeitaria & 50 \\
\hline Atividade Complementar & 450 \\
\hline
\end{tabular}

A carga horária do semestre é, então, organizada em formato de blocos que contemplam os conceitos e sua aplicação no projeto, além das atitudes que se deseja que o profissional que irá trabalhar tais conceitos e aplicações desenvolva. Cada bloco tem carga total de $10 \mathrm{~h}$, sendo o número de blocos de cada semestre dependente da carga horária total do semestre (excetuando-se a carga horária com atividades complementares, estágios e trabalhos de conclusão). Por exemplo, pensando em um curso com carga horária semestral igual a 400h, o estudante cumprirá 40 blocos no semestre. Desses, uma parte pode ser obrigatória e outra opcional. Assim, como exemplo, a coordenação poderá ofertar 60 blocos no semestre (30 obrigatórios e 30 complementares). $\mathrm{O}$ estudante cumpre, portanto, os 30 obrigatórios e outros dez são opcionais (estudante escolhe dez dentre os 30 blocos complementares ofertados), compondo o total necessário de 40 blocos no semestre e, portanto, as 400 horas.

O papel do docente depende da atividade a ser desenvolvida (AAD, PODC ou Preceptoria). Então, vamos definir o papel do docente para cada uma dessas atividades:

- Nos momentos de atividades autodirigidas, o professor deve auxiliar os estudantes no estudo dos conceitos relativos àquela aula. Os estudantes vão fazer esse estudo através do Ambiente Virtual de Aprendizagem, e é importante que o docente conheça o ambiente para poder ajudá-los. Essa atividade é autônoma.

- Nas práticas orientadas para o desenvolvimento de competências, sempre seguindo o planejamento, o docente deverá fazer o aprofundamento de um determinado conceito. Essa atividade é a que mais se assemelha a uma aula, com a diferença que esses conceitos devem ser trabalhados sempre de forma ativa, utilizando-se de metodologias presenciais como Peer Instruction (aprendizado com os colegas) e Team Based Learning (aprendizado em times) ou por meio de demonstrações em vídeo-aulas, por exemplo.

- Por fim, nas atividades de preceptoria, o docente deve fazer o acompanhamento do andamento dos projetos, orientar cada projeto individualmente e orientar o 
estudante na melhoria contínua. É papel do preceptor corrigir deficiências conceituais (teoria aplicada nos projetos), procedimentais (forma como a teoria está sendo aplicada) e atitudinais (atitude do estudante diante dos desafios). Para isso, é importante saber ouvir e saber dar os feedbacks, sempre visando a melhoria do processo e nunca em formato de crítica.

Com as alterações propostas, o método de avaliação também precisa ser alterado para que os objetivos de aprendizagem sejam alcançados. Dessa forma, propõe-se que as avaliações sejam processuais (ocorram naturalmente durante o processo) de forma que se possa corrigir eventuais falhas também durante o semestre, minimizando o número de reprovações e favorecendo o aprendizado efetivo. Além disso, o processo avaliativo está firmado na avaliação das competências conceituais, procedimentais e atitudinais, forma como todo o projeto encontra-se construído.

Desse modo, foram construídas seis abordagens de avaliação que devem ocorrer ao longo do semestre:

1. Avaliação Integrativa - é uma avaliação externa e segue o padrão institucional, sendo somativa regulatória, cuja finalidade é analisar o processo de aprendizagem de forma sistêmica e capacitar os alunos a realização de avaliações em larga escala, como os concursos públicos e avaliações governamentais;

2. Avaliação Conceitual - caracteriza-se por ser somativa, contemplando os conteúdos estudados durante as aulas, sendo composta por questões dos diversos eixos de conteúdo;

3. Avaliação Atitudinal - é uma avaliação bilateral formativa, que ocorre mensalmente, em que os estudantes, por meio de autoavaliação e professores, por meio de observação, acompanhamento e orientação, analisam as competências atitudinais e profissionais dos estudantes;

4. Avaliação Reflexiva (portfólio) - é um modelo formativo processual que visa observar as competências conceituais e atitudinais dos estudantes e se utiliza da ferramenta educacional portfólio;

5. Avaliação de Acompanhamento do Projeto - configura-se num modelo triangular, formativo-somativo, cuja finalidade principal é promover a interação e troca de conhecimentos entre os estudantes, estimulando o trabalho em equipe, além de possibilitar a consecução de projetos finais mais consistentes, uma vez que acompanha todas as fases de estruturação do mesmo;

6. Avaliação do Projeto Final - corresponde à avaliação do projeto final e tem caráter somativo-formativo. 